\title{
Factores que intervienen para la implementa- ción de estrategias de enseñanza-aprendizaje en el aula en telesecundarias.
}

\author{
Narda González Uribe ${ }^{1}$ \\ Lizeth Pérez Pérez ${ }^{2}$ \\ Asesor: Esther Fragoso Fernández
}

\section{Resumen}

La investigación que fue realizada en el municipio de Juárez y Tlahuitepa, Hgo., tenía como objetivo identificar qué factores intervienen para la implementación de estrategias de enseñanza-aprendizaje en el aula en telesecundarias, y juntos con la aplicación de instrumentos obtuvimos que los factores que más intervienen son los estilos de aprendizaje de los alumnos y los recursos materiales disponibles. Los resultados que se obtuvieron fueron sustentados con autores que abordan el mismo tema desde una mirada pedagógica.

Para poder llevar a cabo la investigación se tuvo que ahondar en lo que es la investigación cualitativa y sus características, para así posteriormente saber a qué se asiste a una comunidad.

\section{Introducción}

En la presente investigación abordaremos el tema "factores que intervienen para la implementación de estrategias de enseñanzaaprendizaje en el aula en telesecundarias", al considerar que el fenómeno de las estrategias tiene gran importancia hoy en día, ya que como menciona González "la clave del éxito consiste en que los profesores descubran cómo aprenden los educandos y cuáles deben ser las secuencias didácticas adecuadas para promover su mayor autonomía moral e intelectual" (González, 2003, p.VII), por lo que consideramos que es necesario que los docentes cuenten con herramientas suficientes para que sus alumnos desarrollen un aprendizaje significativo, también es importante el papel del docente en cuanto a que, no solo debe saber sobre su materia, sino más bien la pedagogía que ésta tiene e implementarla.

\subsection{Planteamiento del problema}

En el modelo educativo de telesecundarias se busca que los alumnos sean autodidactas y para ello se deben implementar diversas estrategias en cada una de las áreas académicas, el sistema funciona mediante la red EDUSAT (http://televisioneducativa.gob.mx), que consiste en que los alumnos vean clases televisadas y a partir de ello el maestro sea un guía para que los alumnos construyan un aprendizaje significativo, es aquí donde el maestro necesita implementar, innovar y crear estrategias de aprendizaje-enseñanza. En algunos casos los maestros suelen ser muy tradicionales en donde solo siguen las estrategias que los libros de SEP les marcan y no existe la habilidad o el interés por implementar estrategias nuevas que se apeguen a los contenidos didácticos. La función del maestro no se puede reducir a la simple transmisión de conocimientos, debe ser un organizador, un constructor y un mediador entre el conocimiento y el alumno.

Nuestro problema a investigar es cómo el maestro determina el uso de cada estrategia a aplicar a los alumnos y qué factores principales intervienen para usar una estrategia.

1 narda_gu@hotmail.com. Sexto semestre de la Licenciatura en Ciencias de la Educación, ULSA Pachuca. 2 acuario_lits_94@hotmail.com. Sexto semestre de la Licenciatura en Ciencias de la Educación, ULSA Pachuca. 


\subsection{Objetivo General}

Determinar cómo los docentes de las telesecundarias del municipio de Juárez y Tlahuiltepa., tomadas en cuenta las comunidades de San Lorenzo, Acapa, San Nicolás y Santa María; deciden el uso de las estrategias educativas para su enseñanza. Todo ello con el fin de brindar aportaciones innovadoras que complementen su tarea educativa en beneficio de la educación de calidad a sus alumnos.

\subsection{Objetivos Específicos}

1. Identificar qué tan efectivas son las estrategias que usan los docentes para su enseñanza en el aula.

2. Determinar cómo es que deciden según el tema y los recursos con los que cuentan, la aplicación de estrategias.

3. Elaborar una antología de tipos de estrategias en el aula para retroalimentar sobre el tema.

\subsection{Preguntas de investigación}

1. ¿Qué factores toman en cuenta los maestros de las telesecundarias para implementar estrategias en un aula?

2. ¿Qué tanto los contenidos, contexto, planes y programas, entre otros factores educativos y sociales, determinan la implementación de estrategias de enseñanza-aprendizaje?

3. ¿Qué tantos recursos materiales, humanos, tiempo e infraestructura influyen en la implementación de estrategias de enseñanza-aprendizaje?

\subsection{Justificación}

Cabe mencionar que esta investigación tiene una relación con Proyecto Educativo Regional Lasallista Latinoamericano, ya que nos invita a transformar la sociedad por medio de un servicio educativo dirigido especialmente a comunidades marginadas (PERLA, 2011).
Nos dirigimos hacia la urgencia "educación de calidad" donde se encuentra la necesidad de: reconocer a los docentes como importantes protagonistas del cambio y hacer de su formación una prioridad. Al hablar de calidad también se refiere a la calidad académica: ¿Qué es lo que se enseña? ¿Cómo se enseña? ¿Cuándo se enseña?, así como la conformación de redes para elegir las herramientas pedagógicas adecuadas y las estrategias a implementar en el aula y todo el ambiente educativo en el cual se encuentre el docente.

De este modo se ven beneficiados:

1. Los maestros, para que tengan herramientas necesarias para brindar una educación completa a los alumnos.

2. Los alumnos, que tengan una educación de calidad que les permita desarrollar desde sus conocimientos hasta sus habilidades.

3. La institución en general, para elevar el prestigio de su institución ya que esta brindará una educación con un alto nivel académico.

\section{Marco Teórico}

\subsection{Marco Histórico}

Las estrategias como concepto tuvieron un gran auge en el entorno militar al tener como función el proyectar, ordenar y dirigir las operaciones militares de tal manera que se consiguiera la victoria, también en este entorno militar los pasos o peldaños que forman una estrategia son llamados "técnicas" o "tácticas" ; es de ese suceso que se origina el concepto que "estrategia" según la Gran Enciclopedia Catalana es "el arte de proyectar y dirigir grandes movimientos militares" (1928 en Monereo, Castelló , Clarianna, Palma y Pérez ,2007, p.23). Es entonces cómo surge este concepto de estrategia y se comienza a utilizar en el ámbito de la escuela. Las estrategias de aprendizaje según Nisbet y Shuckersimith "son procesos 


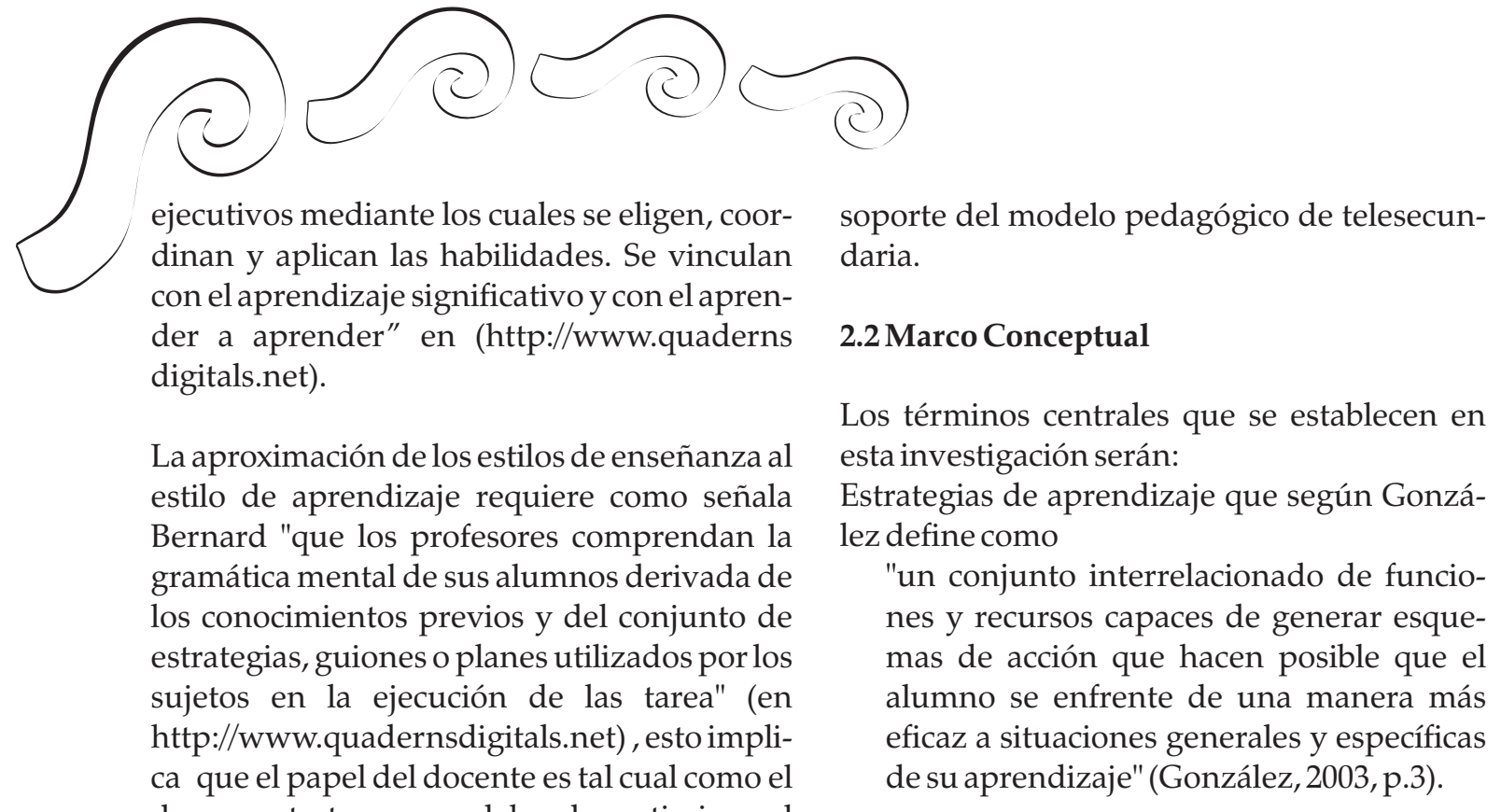
de un estratega que debe de optimizar el aprendizaje para lograr los objetivos deseados y por consiguiente, el alumno también tiene un papel importante porque éste tiene que ser el beneficiado, las estrategias que lleguen a usarse deben de adaptarse al perfil del alumno.

Los estudios sobre estrategias de aprendizaje pueden considerarse como una de las líneas de investigación más fructíferas desarrolladas a lo largo de los últimos años dentro del ámbito del aprendizaje escolar y de los factores que inciden en el mismo. Para algunos autores, las investigaciones sobre las estrategias de aprendizaje junto con la teoría del procesamiento de la información constituyen las aportaciones más relevantes de la psicología cognitiva al estudio del aprendizaje escolar; sin embargo, es importante considerar también las estrategias de enseñanza que completan el circuito del aprendizaje.

Entonces podemos decir que en el modelo de telesecundarias, en el desarrollo de competencias resulta importante contar con una propuesta de estrategias para que los alumnos profundicen, complementen, amplíen y apliquen los aprendizajes obtenidos en el aula y que sean congruentes con el modelo educativo de Telesecundarias. Actualmente las estrategias se integran como actividades que fortalecen la propuesta curricular, lo que es un

Existe una variedad de autores que hablan sobre las estrategias educativas, por otro lado tenemos la definición de Díaz que establece que son "procedimientos que el agente de enseñanza utiliza en forma reflexiva y flexible para promover el logro de aprendizajes significativos en los alumnos" (Enseñanza de enseñanza y aprendizaje, 2002, en http://www.monografias.com).

En nuestro trabajo investigativo conceptualizamos:

a) Estrategias: es una secuencia de procedimientos, técnicas y actividades dirigidas a un objetivo determinado, que es el del proceso de aprendizaje del alumno, para que éste sea significativo.

Otro concepto central que se encuentra en nuestra investigación es el de Telesecundaria que EDUSAT define como "es un modelo educativo a distancia, creado con el objetivo de impartir la educación secundaria a través de transmisiones televisivas en las zonas rurales o de difícil acceso" (http://television educativa.gob.mx), por lo tanto la Secretaria de Educación Pública hace hincapié en mencionar

«'que las estrategias se integran con actividades que fortalecen la propuesta curricular, si bien no todas son obligatorias, expresan un carácter prioritario en su implementación ya que en conjunto con el plan de 


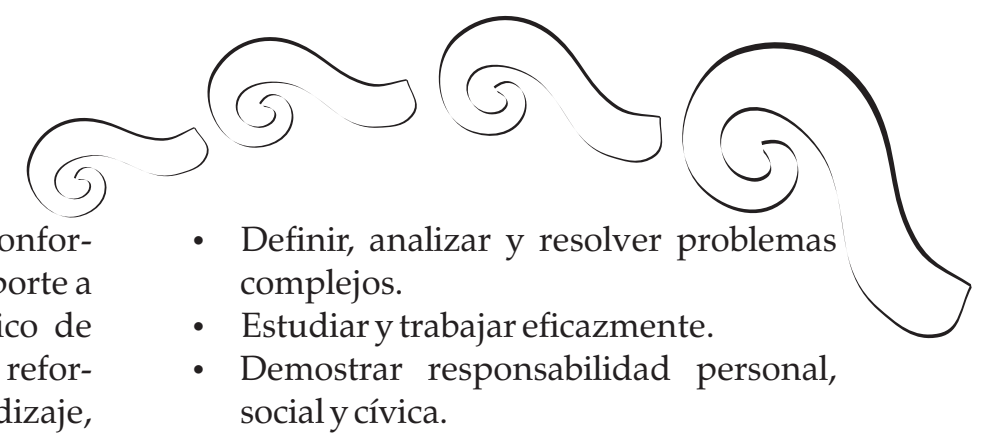

estudios y el diseño institucional conforman la columna vertebral que da soporte a la estructura del modelo pedagógico de Telesecundaria" (en Estrategias de reforzamiento a la formación y a el aprendizaje, 2012, p.5)

En nuestro trabajo investigativo conceptualizamos:

b) Telesecundaria: modelo educativo basado en la transmisión de contenidos educativos mediante una televisión, mediante la red EDUSAT, que se implementa en zonas rurales.

\subsection{Marco Teórico}

Para poder entender qué son las estrategias de enseñanza-aprendizaje es necesario saber que según Zarzar

"el aprendizaje y la enseñanza son dos procesos distintos que los profesores tratan de integrar en uno solo: el proceso de enseñanza-aprendizaje. Por tanto, su función principal no es solo enseñar, sino propiciar que sus alumnos aprendan" (1988, en González, 2003, p.1), uno de los autores a los que nos referiremos en este apartado es González Ornelas Virginia.

\section{González menciona que}

"las estrategias se entienden como un conjunto interrelacionado de funciones $y$ recursos capaces de generar esquemas de acción que hacen posible que el alumno se enfrente de una manera más eficaz a situaciones generales y específicas de su aprendizaje " (González, 2003,p.3), por lo tanto, el alumnos al tener un dominio sobre las estrategias, podrá organizar y dirigir su propio proceso de aprendizaje y puede así potenciar las siguientes capacidades:

- Leer, escribir y comunicarse con eficacia.

- Utilizar las matemáticas, artes, tecnología de computación y otras tecnologías de manera eficaz.

Las estrategias tienen como beneficio, retomando a González, el hecho de que

«'son una vía para que la multiplicidad de significados que se trabajan y comparten en la clase conecten el conocimiento privado que el alumno posee con el conocimiento público que el profesor pretende ensenar" (González, 2003, p.3) , y para poder lograr estos significados, González establece que es lo que debemos diseñar para promover el aprendizaje de los alumnos :

- Saber planificarse: lleva al alumno a determinar tácticas y secuencias para aprender mediante la reducción de una tarea o un problema a sus partes integrantes, el control del propio esfuerzo, no dejar nada para el último momento, etcétera.

- Estar vinculadas con el propio control del aprendizaje, lo que supone la adecuación de esfuerzos, respuestas y descubrimientos a partir de las cuestiones o propósitos que inicialmente se habían planteado.

- Facilitar la reflexión sobre los factores e inconvenientes de progreso en la tarea de aprendizaje.

- Conocer procedimientos para la comprobación de los resultados obtenidos y de los esfuerzos empleados: reclamar la verificación de los pasos iniciales o de los resultados, de acuerdo con las exigencias externas, las posibilidades personales, la planificación realizada y la información que sea dispuesta.

- Utilizar métodos y procesos para la revisión de las tareas y del aprendizaje realizados, lo cual permite al alumno y al profesor rehacer o modificar los objetivos propuestos y señalar otros nuevos, de tal manera que el análisis que se ha derivado de una actividad aprendizaje 


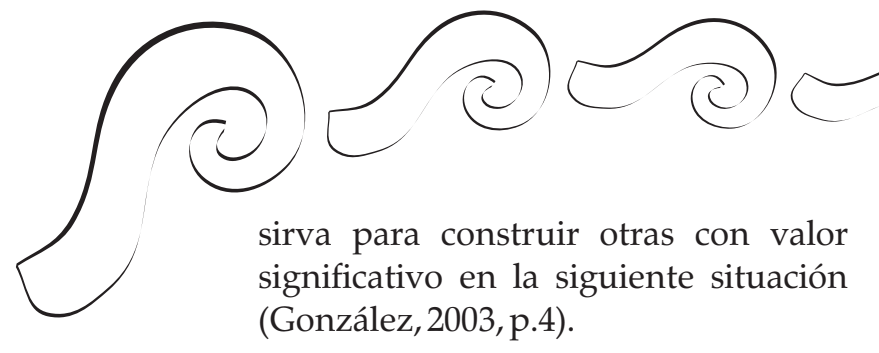

González (2003, p.22) plantea estrategias para tres tipos de desarrollo diferentes, como lo son:

1. Estrategias para el desarrollo cognitivo.

2. Estrategias para el desarrollo de los valores.

3. Estrategias para el desarrollo de la creatividad.

A continuación nos referiremos a las aportaciones de Díaz y Hernández. Es indispensable que en un aula existan estrategias de enseñanza-aprendizaje para que el aprendizaje de los alumnos sea significativo, según Díaz y Hernández "el docente debe poseer un bagaje amplio de estrategias, conociendo qué función tienen y cómo pueden utilizarse o desarrollarse apropiadamente" (Díaz y Hernández, 2002, p.141).

Para la implementación de estrategias influyen distintos factores del contexto social, el escolar y el nivel educativo al cual se les aplicarán las estrategias. Dentro del aula se toman en cuenta distintos aspectos para la aplicación de estrategias, es así cómo es importante retomar lo que el siguiente autor nos menciona;

Díaz y Hernández (2002, p.141) toman en cuenta cinco aspectos importantes que se consideran para saber qué estrategia es la indicada o adecuada en ciertos momentos de la enseñanza:

- Considerar qué características generales tienen los aprendices (nivel de desarrollo cognitivo, conocimientos previos, factores motivacionales, etc.)

- Saber el tipo de dominio del conocimiento en general y del conocimiento curricular en particular, que se va a abordar.

- Intencionalidad o meta que se desea lograr y las actividades cognitivas y pedagógicas que debe realizar el alumno para conseguirla.

- Vigilancia del constante proceso de enseñanza, de las estrategias que se están empleando previamente, el proceso y aprendizaje de los alumnos.

- Determinación del contexto intersubjetivo (conocimiento ya compartido), creado con los alumnos hasta ese momento.

Esto depende de la toma de decisiones del docente para seguir con estos cinco puntos que nos mencionan Díaz y Hernández, los cuales consideramos relevantes para que los docentes tomen en cuenta.

En todo proceso existe un inicio, un desarrollo y un fin o conclusión, al ser así en el proceso de enseñanza-aprendizaje están presentes estos tres tiempos, en donde al inicio de una clase se tienen que aplicar estrategias para la captación de atención del alumno e indagar qué es lo que saben del tema que se va a dar, a eso se le llama inducción. En el desarrollo es necesario involucrar al alumno en la clase, por lo tanto debería existir una integración del alumno, variación del estímulo y preguntas, por lo tanto existen estrategias para esta parte del desarrollado. Al finalizar la clase se deben aplicar estrategias para la evaluación de lo aprendido, las conclusiones.

Díaz y Hernández (2002, p.145) mencionan que las estrategias se pueden aplicar al inicio, durante y al término de una sesión por lo cual les da los siguientes nombres a las estrategias: preinstruccionales, coinstruccionales y postinstruccionales. A esto lo llama episodio de enseñanza-aprendizaje y explica a estos tres momentos de la siguiente manera:

\section{Estrategias preinstruccionales:}

Preparan y alertan al estudiante con qué y cómo va a aprender. Esencialmente tratan de incidir en la activación o la generación del 


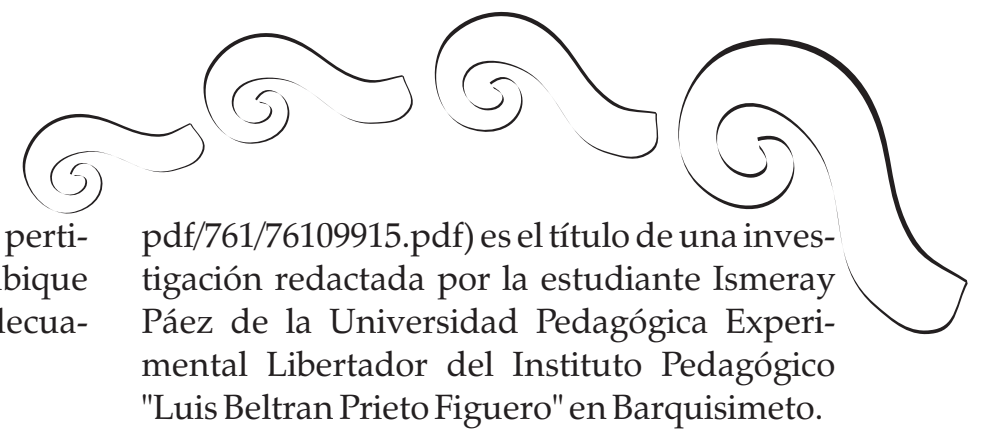

Estrategias coinstruccionales:

Apoyan los contenidos curriculares durante el proceso de enseñanza-aprendizaje. Cubren funciones para que el aprendiz mejore la atención e igualmente detecte la información principal, logre una mejor codificación y conceptualización de los contenidos de aprendizaje y estructura, organice e interrelacione las ideas importantes.

Estrategias postinstruccionales:

Se presentan al término del episodio de enseñanza y permite al alumno formar una visión sintética, integradora e incluso crítica del material y valorar su propio aprendizaje.

Por lo tanto las estrategias que se implementen deben de tener un objetivo y saber que se quiere lograr al aplicarla a los alumnos. Es así como enfatizamos la importancia de la aplicación de estrategias de enseñanza-aprendizaje en el aula.

Se concluye con las aportaciones de ambas autoras, en esta investigación, nos estamos adentrando a la postura de la autora Díaz (2002) en Estrategias docentes para un aprendizaje significativo por su complementariedad en el tema de estrategias de enseñanzaaprendizaje.

\subsection{Marco Referencial}

Existen diversas investigaciones sobre el tema de estrategias de enseñanza-aprendizaje por lo cual consideramos retomar las siguientes investigaciones, las cuales coinciden con la importancia que nosotros le damos a las estrategias y coincidimos con las aportaciones que hacen en cada una de las investigaciones.

"Estrategias de aprendizaje - investigación documental" (http://www.redalyc.org/

Esta investigación aborda temas de diferentes estrategias de aprendizaje estudiadas por los participantes de la III Cohorte de Doctorado en Educación (PIDE) Convenio UCLA-UPELUNEXPO en Barquisimeto. Asimismo contiene información que recopiló la autora en distintas bibliotecas y distintas fuentes electrónicas.

Es importante mencionar que dicha investigación fue llevada a cabo, como ya es mencionado anteriormente en Barquisimeto, Venezuela, lo cual influye en el tipo de información que esta nos brinda, ya que tienen diferentes fuentes de información y es un contexto distinto, pero existen autores que Ismeray retoma que son de nuestro interés como Díaz y Hernández; por lo cual su investigación compagina con la nuestra.

Otro de los temas que refleja esta investigación documental es el de motivar al docente a actuar como mediador entre los contenidos del aprendizaje y la planificación de sus actividades para potenciar el aprendizaje significativo (Ismeray, 2006).

En el desarrollo de su investigación menciona a siete autores con sus respectivas definiciones de estrategias de aprendizaje. En un apartado de su escrito, la autora hace una aportación interesante al tema que ella nombra "Elementos que intervienen en la selección y ejecución de las estrategias de aprendizaje" (Ismeray, 2006) que tiene una estrecha relación con nuestro tema, y aunque en realidad no es el mismo contexto, las dos tienen el mismo objetivo, que es crear un aprendizaje significativo en el alumno, según Ismeray (2006) "los factores personales implican el análisis y la aplicación, para lo cual existe una serie de elementos determinantes tales como: los objetivos del trabajo, los 


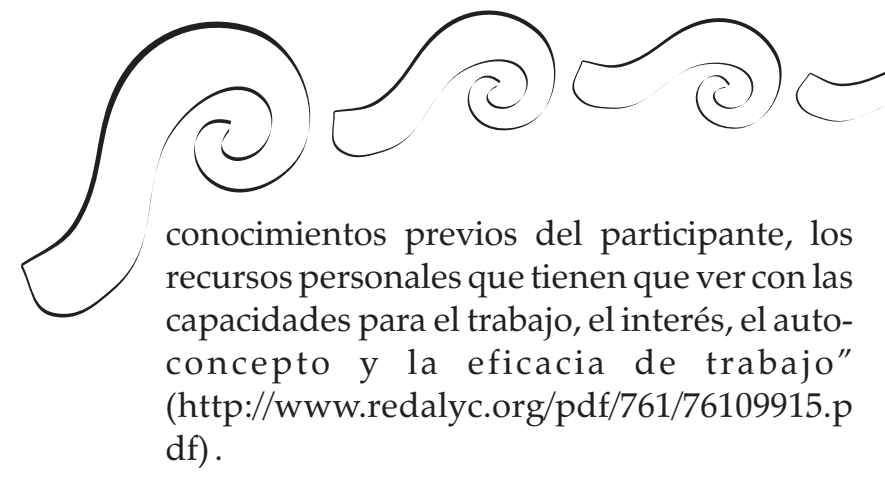

La autora da una serie de estrategias que enriquecen nuestra investigación como lo son:

Estrategias Cognitivas en la Atención: son determinadas por el uso de habilidades de control ejecutivo en el acto de fijar la atención en partes determinadas de un texto impreso y percibirlas selectivamente, para lo cual las preguntas intercaladas son útiles para producir el efecto de activar la atención.

Estrategias Cognitivas en la Codificación: se puede emplear pares de palabras que proporcionen a la persona instrucciones de "elaboración" de oraciones cuya producción dependerá de la propia persona. Estos ejercicios mejoran el aprendizaje de conceptos concretos.

Estrategias de Recuperación: son las que permiten a las personas recuperar los nombres, fechas y acontecimientos; estos se conocen desde hace tiempo y son denominados sistemas mnemónicos. Algunos ejercicios que pueden ser empleados son las imágenes de lugares como ciertos puntos de una habitación conocida para recordar temas sucesivos.

Estrategias Cognitivas en la Solución de Problemas: estas estrategias pueden ejercitarse al plantear un problema y tratar de ubicar diferentes maneras de resolución del mismo; cómo encontrar las características más relevantes del mismo, cómo recordar lo que ya se ha probado antes, cómo evaluar las posibilidades de comprobaciónn de hipótesis, entre otros.

Estos subtemas son rescatables aunque no se refiere a un modelo de telesecundarias, estos se pueden adaptar al modelo y llevarse a cabo, además que le da un sustento a nuestra investigación.
Otra de las investigaciones que retomamos tiene como título: "Importancia de las estrategias de enseñanza y el plan curricular", del el autor Johan Kohler Herrera de la Universidad de San Martin de Porres, Perú.

Nos menciona la importancia que tienen las estrategias de enseñanza-aprendizaje en los planes curriculares, al igual que cita a Díaz y Hernández para establecer la forma de utilizar las estrategias.

Coincidimos con los puntos que menciona Kholer en su investigación, damos por sentado que son referentes de gran importancia para nuestra investigación, ya que nos dan fundamentos válidos para poder sustentar nuestras aportaciones, de la misma forma, nos dan un panorama más amplio sobre lo que nuestro tema se refiere a "la implementación de estrategias de enseñanza".

\section{Metodología}

\subsection{Enfoque}

La investigación adquiere un enfoque cualitativo de tendencia, esto quiere decir que los sucesos que estudia son naturales; es por eso que existe una inmersión inicial en el campo, donde los investigadores observan el caso, fenómeno, sujeto de forma natural sin alterarlo, por lo que en nuestra investigación es muy importante el contacto con las personas que intervienen en el fenómeno, Otras características del enfoque cualitativo que adquiere por igual nuestra investigación es que ésta adopta un proceso inductivo, lo que quiere decir que primero explora y describe a un fenómeno en particular, para así generar perspectivas teóricas generales. Este enfoque implica flexibilidad ya que se debe estar moviendo entre los eventos y su interpretación, así también como de los resultados obtenidos mediante una triangulación y el desarrollo de la investigación. 


\subsection{Contexto}

El contexto en donde se realizó la investigación fue en el municipio de Juárez y Tlahuiltepa en las Telesecundarias de la comunidad de San Lorenzo, Acapa, San Nicolas y Santa María.

\subsection{Diseño de la investigación}

El diseño de nuestra investigación es no experimental, ya que la situación que vamos a atender no será manipulada y nos basaremos principalmente en la observación de fenómenos en el contexto natural para después analizarlos, en este caso nuestras variables serían los docentes y estrategias de enseñanza- aprendizaje, variables que nos interesa analizar desde su manera natural y sin alterarlas. Describiremos variables (docente-estrategias) analizando la interrelación e influencia en un único momento dado, por lo cual será transeccional.
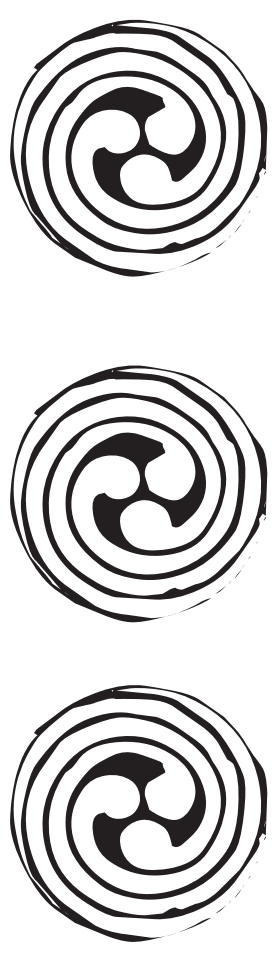

\subsection{Alcance de la investigación}

El alcance del estudio es un elemento muy importante, ya que de éste se desglosan las estrategias de investigación, el diseño y los procedimientos. En este caso, nuestra investigación incluye el alcance descriptivo que según Danhke son "los que buscan especificar las propiedades, las características y los perfiles de personas, grupos, comunidades, procesos, objetos o cualquier otro fenómeno que se someta a un análisis" (Danhke, 1989, en Sampieri 2006, p.102), por lo cual en nuestra investigación pretendemos identificar las características y factores que intervienen para la aplicación de estrategias al describir el rol del docente y el alumno en este proceso de enseñanza aprendizaje.

\subsection{Sujetos, universo y muestra}

Los sujetos que hicieron posible la realización de la investigación fueron los padres de familia, maestros y alumnos de cada comunidad.
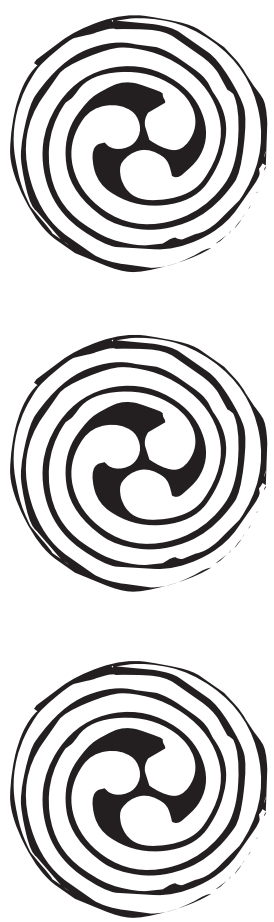


\subsection{Instrumentos de recolección}

Los instrumentos que se les aplicaron fueron los siguientes:

Folio:

\section{GUIA DE OBSERVACIÓN}

\begin{tabular}{|l|l|}
\hline PROFESOR: & GRADO Y GRUPO: \\
\hline MATERIA: & NOMBRE DE LA INSTITUCIÓN: \\
\hline
\end{tabular}

Desempeño a evaluar. El docente en su práctica educativa, hace uso de estrategias de enseñanzaaprendizaje al inicio, en el desarrollo y al final de su clase, logrando en sus alumnos un aprendizaje significativo.

\begin{tabular}{|c|c|c|c|c|c|}
\hline \multirow{2}{*}{ No. } & \multirow{2}{*}{ Acciones a evaluar } & \multicolumn{3}{|c|}{$\begin{array}{l}\text { Registro de } \\
\text { cumplimiento }\end{array}$} & \multirow{2}{*}{ Observaciones } \\
\hline & & SI & $\mathrm{NO}$ & NA & \\
\hline 1 & Aplicación de estrategias al inicio de la clase. & & & & \\
\hline 2 & $\begin{array}{l}\text { Participación de todos los alumnos en la dinámica } \\
\text { grupal. }\end{array}$ & & & & \\
\hline 3 & El docente atiende dudas. & & & & \\
\hline 4 & $\begin{array}{l}\text { El docente aplica estrategias durante el proceso de } \\
\text { enseñanza-aprendizaje, para relacionar los temas y } \\
\text { aclarar dudas. }\end{array}$ & & & & \\
\hline 5 & $\begin{array}{l}\text { Los alumnos muestran interés ante la clase por el tipo } \\
\text { de estrategias que el docente aplica. }\end{array}$ & & & & \\
\hline 6 & $\begin{array}{l}\text { Al finalizar la clase el docente aplica actividades de } \\
\text { cierre con los alumnos, para identificar lo aprendido } \\
\text { y evaluar su aprendizaje. }\end{array}$ & & & & \\
\hline 7 & $\begin{array}{l}\text { Usa distintos tipos de materiales para la aplicación de } \\
\text { estrategias. }\end{array}$ & & & & \\
\hline 8 & Tiene un tiempo de aplicación de cada estrategia. & & & & \\
\hline
\end{tabular}

Nombre del observador:

Fecha: 
Los sujetos que hicieron posible la realización de la investigación fueron los padres de familia, maestros y alumnos de cada comunidad y los instrumentos que se les aplicaron fueron los siguientes:

Factores que intervienen para la implementación de estrategias de enseñanza-aprendizaje en el aula en Telesecundarias

\section{ENTREVISTA MAESTROS}

Nombre de la institución

Folio

Nombre

Sexo: masculino( )femenino( ) Comunidad

1. ¿Qué tan importante son las estrategias de enseñanza-aprendizaje en su práctica docente?

¿Por qué son o no son importantes?

2. ¿Cuál es su propósito cuándo implementa estrategias de enseñanza-aprendizaje?

A. Que repasen lo visto en clase

B. Que tengan un aprendizaje significativo

C. Que plasmen en la estrategia lo que aprendieron en la clase

D. Que las usen como método de estudio

E. Cumplir con el programa curricular

F. Otro

3. ¿Qué tan efectivas son sus estrategias al implementarlas a sus alumnos?

¿Por qué?

4. ¿Qué beneficio obtienen sus alumnos cuándo se implementan buenas estrategias?

A. Calificaciones aprobatorias en los exámenes

B. Adquieren un aprendizaje significativo

C. Los alumnos se sienten contentos por sus logros académicos

D. Se interesan más por aprender en la clase

E. Sienten que la clase es más motivadora

F. Otro 
5. ¿Qué factores influyen en la decisión de qué estrategia va a aplicar?
A. El proceso y estilo de aprendizaje de los alumnos
B. El tema que se esté llevando a cabo
C. La cohesión o desintegración del grupo
D. El contexto/ambiente general
E. Recursos disponibles
F. Otro

6. ¿Toma en cuenta el perfil de sus alumnos para implementar las estrategias?
A. Devez en cuando
B. Frecuentemente
C. Casinunca
D. Nunca
E. Siempre
F. Otro

7. ¿Con qué dificultades se encuentra al aplicar estrategias en el aula?
A. Falta de convivencia en el salón
B. Carencia de recursos
C. Dificultad al vincular los temas con una estrategia
D. Escaso conocimiento de tipos de estrategias
E. No dificultades
F. Otro

8. ¿Qué recursos intervienen para que una estrategia sea usada?
A. Recursos didácticos
B. Económicos
C. Recursos humanos
D. Factores sociales
E. Todos los anteriores
F. Otro
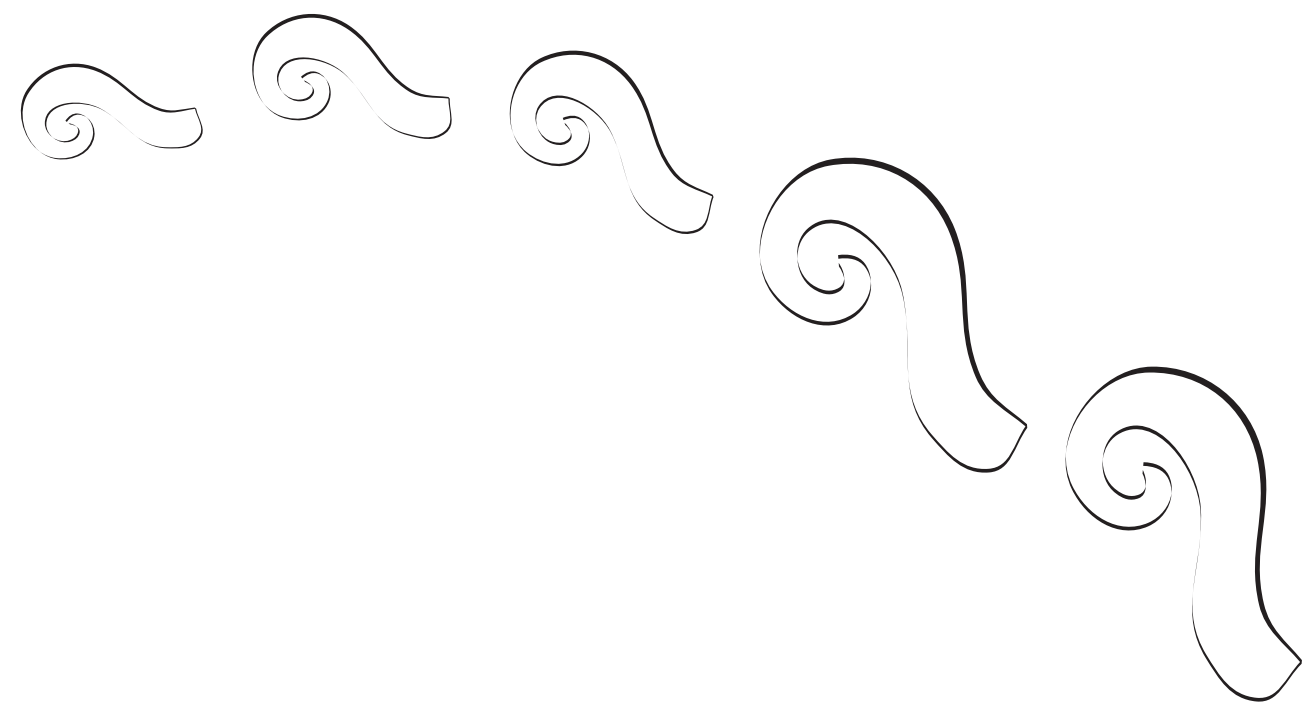


\section{Factores que intervienen para la implementación de estrategias de enseñanza-aprendizaje en el aula en Telesecundarias \\ ENTREVISTA PADRES}

Folio

Nombre de la institución

Nombre Grado

Sexo: masculino ( ) femenino( ) Comunidad

1. ¿Para usted qué tan importante son las estrategias de enseñanza- aprendizaje en un salón de clases?

A. Solo son reforzamientos para que los alumnos entiendan mejor el tema.

B. Poco importantes.

C. importantes, sirven de complemento

D. Muy importantes

E. Es lo más importante porque son recursos que ayudan a la correcta representación del conocimiento del alumno.

F. Otro

2. ¿Cuál cree usted qué sea lo que los maestros quieren lograr cuando usan estrategias enseñanza-aprendizaje?

A. Que los alumnos se aprendan todo de memoria

B. Que los alumnos repasen lo visto en clase

C. Que los alumnos tengan un aprendizaje que les permita resolver diferentes situaciones

D. Que los alumnos usen las estrategias para que estudien en casa

E. Para cumplir con lo que la escuela dice

F. Otro

3. ¿Cómo sabe que las estrategias que los docentes le aplican a sus hijos, les sirven?

A. Porque hacen sus tareas con entusiasmo y sin dudas

B. Por sus calificaciones

C. Porque me cuenta lo que aprendió en clases sin dificultades

D. Porque habla sobre aspectos positivos de su maestro

E. No me doy cuenta de los resultados de la aplicación de estrategias

F. Otro

4. ¿Qué beneficio educativo cree que tiene su hijo cuándo trabaja con distintas actividades?

5. ¿Qué factores internos a la escuela, influyen en la formación educativa de sus hijos?

A. La forma en que aprenden

B. El tema que se estéllevando a cabo

C. La unión o desintegración del grupo

D. El contexto/ambiente general

E. Recursos disponibles

F. Otro 
6. ¿Cree qué es importante que el docente tome en cuenta las características personales de sus hijos?

¿Para qué?

7. ¿Cuáles son las dificultades que usted conoce para que el docente aplique estrategias en aula?
A. Falta de convivencia en el salón
B. Falta de recursos
C. Dificultad al unir los temas con una estrategia
D. Poco conocimiento de tipos de estrategias
E. No dificultades
F. Otro

8. ¿Qué factores intervienen para que su hijo tenga un desempeño adecuado en la escuela?

A. Alimentación balanceada y saludable

B. Atención fraternal

C. Maestros con buen desempeño académico

D. La convivencia con sus pares

E. Trabajo colaborativo entre comunidad escolar y padres

F. Otro

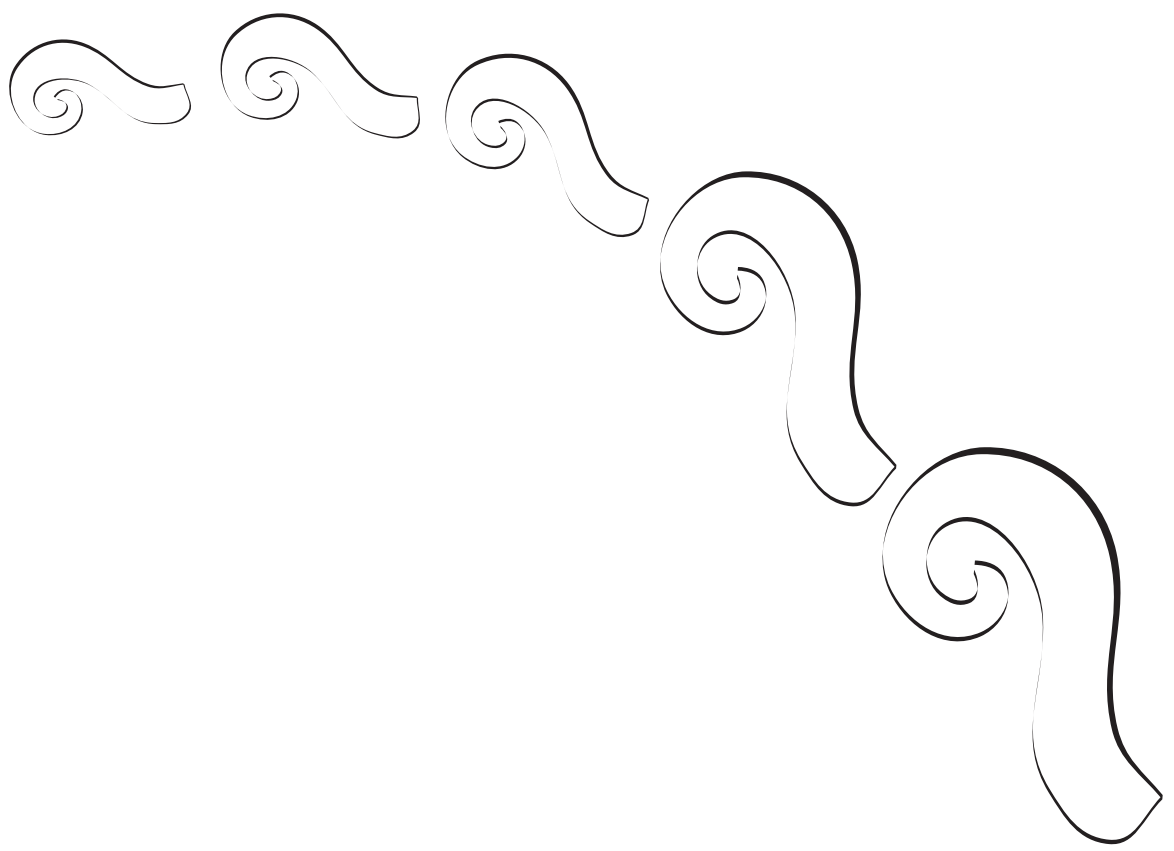


Factores que intervienen para la implementación de estrategias

de enseñanza-aprendizaje en el aula en Telesecundarias

ENTREVISTA ALUMNOS

Folio

Nombre de la institución

Nombre

Grado

Sexo: masculino( )femenino( ) Comunidad

1. ¿Qué tan importante son las estrategias de enseñanza-aprendizaje para tu desempeño académico?

A. Me gusta usarlas como repaso

B. Poco importantes

C. Importantes, sirven de complemento

D. Muy importantes

E. Es lo más importante porque son recursos que ayudan a reforzar mi conocimiento y que al aprender algo no se me olvide

F. Otro

2. ¿Cuál sería el propósito de cumplir con las estrategias de enseñanza-aprendizaje que el docente establece?

A. Que se memorice el contenido

B. Que se repase lo visto en clase

C. Que se tenga un aprendizaje que pueda usar en la vida diaria

D. Que se plasme en la estrategia lo que se aprendió en la clase

E. Que se usen como método de estudio

F. Otro

3. ¿Cuáles son los beneficios cuándo tu maestro trabaja con buenas estrategias?
A. Calificaciones aprobatorias en los exámenes
B. Un aprendizaje significativo
C. Satisfacción de logros académicos
D. Interés por aprender en la clase
E. Clase más motivadora
F. Otro

4. ¿Qué factores influyen en la implementación de estrategias que el docente aplica?
A. En la manera en que aprenden los alumnos
B. El tema que se estéllevando a cabo
C. La unión o desintegración del grupo
D. El contexto/ambiente general
E. Recursos disponibles
F. Otro

5. El docente itiene un acercamiento con ustedes? 
¿De qué forma?

6. ¿Qué dificultades encuentras en el docente para implementar las estrategias?
A. Falta de convivencia en el salón
B. Falta de recursos
C. Poco conocimiento de tipos de estrategias
D. Todas las anteriores
E. No dificultades
F. Otro

7. ¿Qué recursos intervienen cuando tu docente te aplica una estrategia?
A. Materiales
B. Económicos
C. Alumnos
D. convivencia
E. Todos los anteriores
F. Otro

8. Enlista las tres principales maneras de enseñar que usan regularmente tus maestros A.

B.

C.

¿Te sirven?

¿Por qué?
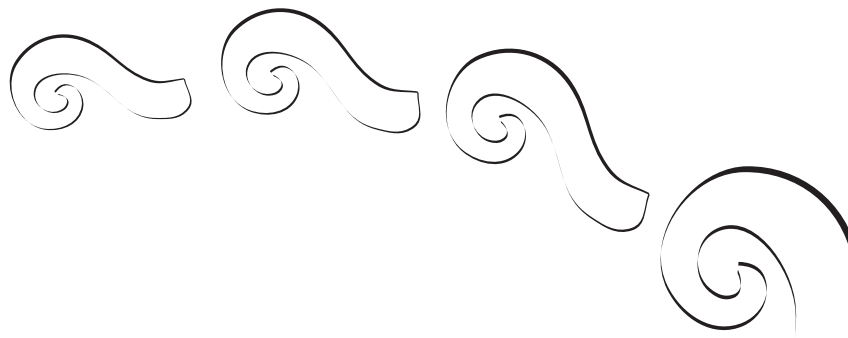


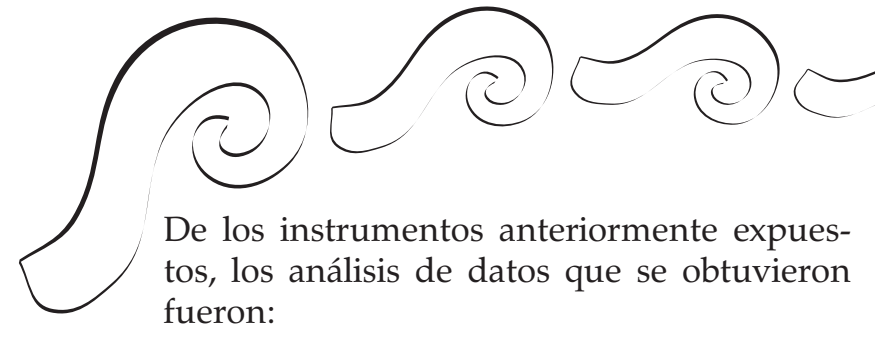

3.7 Análisis de los instrumentos

\section{Entrevista a alumno. San Lorenzo}

El día 10 de noviembre del 2014, se hicieron seis entrevistas a los alumnos de la Telesecundaria no. 22 localizada en la comunidad de San Lorenzo; del total de los alumnos entrevistados el $50 \%$ clasifica a las estrategias de enseñanza- aprendizaje como "muy importantes" ya que ayudan a reforzar el conocimiento. "El propósito de las estrategias es plasmar en éstas lo que se aprendió en la clase", es la respuesta que proporciona el $50 \%$ de los alumnos, mientras el $20 \%$ afirma que las estrategias tienen el propósito de ser usadas como repaso para la clase, el $50 \%$ de los alumnos afirman que el beneficio del uso de buenas estrategias por parte de los maestros es obtener un aprendizaje significativo, en otra pregunta el $33.3 \%$ de los alumnos indican que la manera de aprender de cada uno es lo que más influye en la aplicación de estrategias.

El 66.6\% de los alumnos no encuentra dificultades en los maestros para implementar estrategias, en cambio el $33.3 \%$ piensa que una dificultad es la falta de convivencia en el salón, la mitad de los jóvenes establece que los recursos materiales son los que más intervienen cuando un maestro aplica una estrategia. Por otro lado, el $33.3 \%$ de ellos menciona que la convivencia es lo que más interviene en la aplicación de una estrategia.

Los alumnos mencionaron dos estrategias que usan con frecuencia sus maestros, que son las dinámicas, ya sean fuera o dentro del aula y el uso de recursos tecnológicos incluidos en estos la clase televisada.

\section{Entrevista a maestros. San Lorenzo}

Telesecundaria no. 22 localizada en la comunidad de San Lorenzo, en donde el $75 \%$ de ellos tiene como propósito al implementar estrate- gias, que los alumnos adquieran un aprendizaje significativo. En otra pregunta, la mitad de los maestros responden que los beneficios que pueden obtener sus alumnos al implementar buenas estrategias es que se interesen más por aprender en la clase, mientras la otra mitad afirma que es la motivación en la clase; el $25 \%$ piensa que el estilo de aprendizaje de los alumnos es lo que más influye en la estrategia que se va a aplicar, por otro lado, el $25 \%$ responde que lo que más influye es el contexto en general. Más de la mitad de los docentes afirma que frecuentemente toma en cuenta el perfil de los alumnos para implementar las estrategias, mientras el $25 \%$ que resta afirma que siempre toma en cuenta el perfil de los alumnos, la mitad de los maestros respondió que no existen dificultades al llevar a cabo estrategias en el aula, en cambio, la otra mitad respondió que la dificultad que tienen al implementar estrategias es la carencia de recursos.

\section{Entrevista a padres. San Lorenzo}

El día 10 de noviembre del 2014 se hicieron cuatro entrevistas a los padres de familia de la Telesecundaria no. 22 localizada en la comunidad de San Lorenzo, del 100\% de los padres entrevistados, el $25 \%$ establece que las estrategias de enseñanza-aprendizaje son solo reforzamientos para que los alumnos entiendan mejor el tema, en cambio el $75 \%$ las encuentran importantes; de ese porcentaje el 50\% menciona que son lo más importante ya que sirven para reforzar los conocimientos de los alumnos, la mitad de los padres piensa que la razón por la cual los maestros aplican estrategias es para cumplir con lo que la escuela dice. El 25\% de los padres sabe que las estrategias que los docentes le aplican a sus hijos les sirven debido a las calificaciones que presentan, el otro $25 \%$ porque hablan aspectos positivos de sus maestros y el $50 \%$ porque les cuentan lo que aprendieron en clases sin ninguna dificultad. La mitad de los padres de la comunidad de San Lorenzo concuerdan con que el factor que más influye en la formación académica de sus hijos es la forma en que cada uno aprende, 


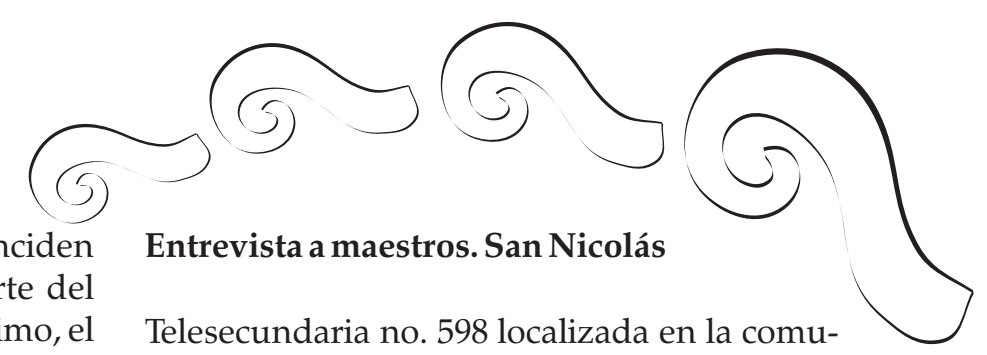

por otro lado, el $50 \%$ de los padres coinciden en que no existen dificultades por parte del docente para aplicar estrategias. Por último, el $100 \%$ de los padres de familia encuentran como el factor de intervención más importante para el desempeño de sus hijos, el trabajo colaborativo entre comunidad escolar y padres.

\section{Entrevista a alumno. San Nicolás.}

El día 13 de noviembre del 2014, se hicieron seis entrevistas a los alumnos de la Telesecundaria no. 598 localizada en la comunidad de San Nicolás. En las entrevistas el $83.3 \%$ de los alumnos consideran que lo más importante para su desempeño académico sí son las estrategias de enseñanza-aprendizaje, ya que éstas refuerzan el aprendizaje y ayudan a que los contenidos no se olviden; por otro lado, el $33.3 \%$ de los alumnos piensan que el propósito por el cual los maestros deben de cumplir con estrategias es para que tengan un aprendizaje que puedan usar en la vida diaria, el otro $33.3 \%$ contestó que el propósito es usarlas como método de estudio, en cambio el $16.6 \%$ establece que es repasar lo que se vio en clase y el $16.6 \%$ restante menciona que es plasmar en la estrategia lo que aprendieron. La mitad de los alumnos contestó que el beneficio de la aplicación de una buena estrategia es el aprendizaje significativo, los factores que influyen en la implementación de estrategias que el docente aplica, mientras que para el 83.3\% de los alumnos son la manera en que ellos aprenden, más de la mitad de los alumnos no encuentran dificultades en la aplicación de estrategias por parte de sus maestros; para el $33.3 \%$ de los jóvenes, los factores que intervienen cuando el docente aplica una estrategia son materiales, económicos, humanos y la convivencia.

Los alumnos de la Telesecundaria no. 589 afirman que las estrategias más usadas por sus docentes son los ejemplos, esta forma de exponer los temas agrada mucho a los alumnos, ya que les facilita el poder relacionar el tema con la realidad. nidad de San Nicolás. El 100\% de la población docente contestó que el propósito de la implementación de las estrategias de enseñanzaaprendizaje es que los alumnos adquieran un aprendizaje significativo, el $62.5 \%$ de los maestros responde que los beneficios que los alumnos obtienen de una buena estrategia es que se interesen más en aprender durante la clase, mientras que el $33.3 \%$ restante piensa que el beneficio es que se sientan motivados en la clase. El 100\% de los entrevistados concuerdan con que los factores que más influyen en la decisión de qué estrategia se va a aplicar es el proceso y estilo de aprendizaje de los alumnos, el $62.5 \%$ de los docentes frecuentemente toma en cuenta el perfil de sus alumnos, mientras el 33.3\% lo toma siempre: El estado de ánimo de los alumnos es la dificultad que encuentra el $62.5 \%$ de los docentes para aplicar una estrategia antes planeada. Por ultimo, el 33.3\% responde que los recursos que más interviene para que una estrategia sea usada con los recursos didácticos, mientras el 33.3\% dice que son los humanos, en cambio el $33.3 \%$ restante confirma que son los anteriores más los recursos económicos y sociales.

\section{Entrevista a padres. San Nicolás}

El día 13 de noviembre del 2014 se hicieron cuatro entrevistas a los padres de familia de la Telesecundaria no. 598 localizada en la comunidad de San Lorenzo, la mitad de los padres consideran que las estrategias de enseñanzaaprendizaje son muy importantes para sus hijos, también, el $50 \%$ de los padres coincide con que los maestros hacen uso de las estrategias para cumplir con lo que la escuela dice; por otro lado, el 75\% de los padres de familia afirman que las estrategias que los maestros aplican a sus hijos son adecuadas porque les cuentan lo que aprendieron en la clase sin dificultades, para el $25 \%$ de los papás los factores internos a la escuela que influyen en la formación educativa de sus hijos son el tema que se está llevando a cabo, el $25 \%$ establece 


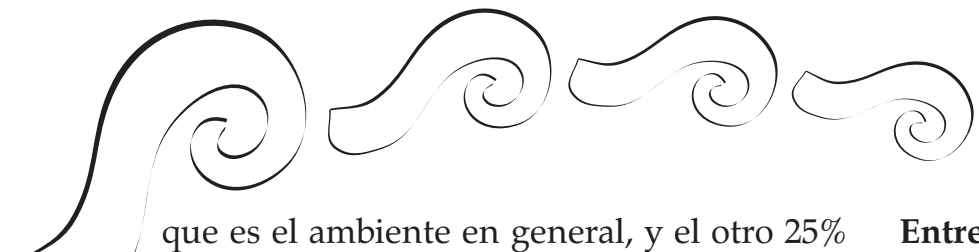

que es el ambiente en general, y el otro 25\% establece que son los recursos disponibles. La mitad de los padres concuerda en que las dificultades con que los maestros se enfrentan al aplicar estrategias son la carencia de recursos, el $25 \%$ de los padres contestó que los factores que más intervienen en el desempeño de sus hijos es la atención fraternal, otra respuesta en donde el otro $25 \%$ de padres concuerda es que lo que interviene es la convivencia con sus pares. Por último, el $25 \%$ restante dice que es el trabajo colaborativo entre comunidad escolary padres.

\section{Entrevista a alumno. Acapa}

El día 12 de noviembre del 2014 se hicieron seis entrevistas a los alumnos de la Telesecundaria no.110 localizada en la comunidad de Acapa.

El $100 \%$ de los alumnos considera que las estrategias son muy importantes y el 50\% mencionó que es importante porque ayudan a reforzar su conocimiento, el 33.3\% mencionó que los propósitos de la aplicación de estrategias es un aprendizaje que pueden usar en la vida diaria, el otro $33.3 \%$ dijo que el propósito es plasmar en las estrategias lo que se aprendió en la clase y por último el $33.3 \%$ mencionó que es un método de estudio para tener calificaciones aprobatorias en los exámenes. La manera en que aprenden los alumnos es un factor influyente en la aplicación de estrategias, por lo que es lo que respondió la mitad de los alumnos, $16.6 \%$ menciona que lo que influye en la aplicación de estrategias es el tema que se esté llevando acabo. Más de la mitad de los alumnos coincide en que no hay dificultades para la implementación de una estrategia, sin embargo el $33.3 \%$ establece que la dificultad que existe es la falta de convivencia. La mitad de los alumnos menciona que los recursos materiales, económicos, alumnos y convivencia, intervienen para que un docente aplique una estrategia, afirma el $66.6 \%$ que las estrategias más utilizadas en el salón son dinámicas y exposiciones, seguidas por trabajo en equipo e hipótesis.

\section{Entrevista a maestros. Acapa}

El día 12 de noviembre se hicieron dos entrevistas a los maestros de la Telesecundaria no. 110 localizada en la comunidad de Acapa.

Todos los docentes establecen como propósito de la implementación de las estrategias, el aprendizaje significativo de sus alumnos. El $50 \%$ de los docentes consideran que el factor que influye para la aplicación de estrategias es el proceso y estilo de aprendizaje de los alumnos, y la otra mitad establece que es el tema que se está llevando. La mitad de los docentes toma en cuenta siempre el perfil de los alumnos para la implementación de una estrategia y la otra mitad toma frecuentemente en cuenta este aspecto. El $50 \%$ de los docentes dice que la dificultad para la aplicación de estrategias es la carencia de recursos, mientras que el otro $50 \%$ encuentra que la dificultad es que los alumnos no tienen los conocimientos que deberían tener en el nivel en el que se encuentran. El $100 \%$ de los docentes afirma que los recursos didácticos intervienen para que una estrategia sea usada.

\section{Entrevista a padres. Acapa}

El día 12 de noviembre del 2014 se hicieron cuatro entrevistas a los padres de familia de la Telesecundaria no. 110 localizada en la comunidad de Acapa. El 100\% de los padres de familia consideran que las estrategias de enseñanza-aprendizaje son importantes, sin embargo el $75 \%$ mencionan que las estrategias son lo más importante porque son recursos que ayudan a la correcta representación del conocimiento del alumno. La mitad de los padres de familia establecen que el maestro quiere lograr en los alumnos un aprendizaje que les permita resolver diferentes situaciones, el 25\% dice que lo que quiere lograr es que los alumnos repasen lo visto en clase, el otro $25 \%$ restante menciona que el docente pretende que los alumnos usen las estrategias para que estudien en casa. La mitad de los padres de familia piensan que las estrategias que se les aplica a sus hijos sirven, ya que los alumnos hablan de aspectos positivos de su maestro, la otra mitad 


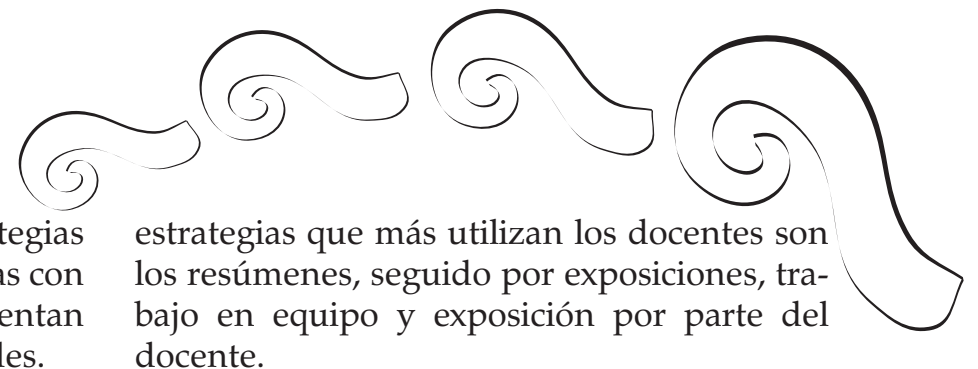

afirma que se dan cuenta que las estrategias les sirven a sus hijos porque hacen tareas con entusiasmo, sin dudas y porque les comentan lo que aprendieron en clase sin dificultades.

El 50\% de padres establece que no hay dificultades para que los maestros apliquen estrategias, pero el $25 \%$ dice que existe carencia de recurso lo cual es una dificultad para la aplicación de estrategias. El 50\% de los padres menciona que el factor que interviene para el mejor desempeño de sus hijos es la alimentación balanceada y saludable, mientras que el $25 \%$ dice que influye que el maestro tenga un buen desempeño académico, finalmente el $25 \%$ restante menciona que lo que interviene es el trabajo colaborativo entre comunidad escolar y padres.

\section{Entrevista a alumno. Santa María}

El día 11 de noviembre del 2014 se hicieron seis entrevistas a los alumnos de la Telesecundaria no.346 localizada en la comunidad de Santa María. El 83.3\% de los alumnos piensan que las estrategias es lo más importante porque son recursos que ayudan a reforzar su conocimiento y que al aprender algo no se les olvide, y el $16.6 \%$ restante considera que son importantes porque sirven de complemento. El 33.3\% de los alumnos dice que el propósito de las estrategias es que repasen lo visto en clase, el otro $33.3 \%$ considera que el propósito de las estrategias es que tengan un aprendizaje que puedan usar en la vida diaria, el 33.3\% restante establece que las estrategias son un método de estudio. Los beneficios que encuentra el $83.3 \%$ de los alumnos es que su maestro trabaje con estrategias para lograr un aprendizaje significativo, y el 16.6\% considera que el beneficio es crear un interés por aprender en clase. La mitad de los alumnos mencionan que el factor que intervienen para la aplicación de una estrategia es el tema que se esté viendo, el 33.3\% la manera en que aprenden los alumnos y el $16.6 \%$ la unión o desintegración del grupo. Las dificultades que encuentran en el docente son: $66.6 \%$ la falta de convivencia y el $33.3 \%$ no encuentra ninguna dificultad. El 50\% de los alumnos afirma que las

\section{Entrevista a maestros. Santa María}

El día 11 de noviembre del 2014 se hicieron cuatro entrevistas a los maestros de la Telesecundaria no. 346 localizada en la comunidad de Santa María. El 100\% de los docentes tiene como propósito el implementar estrategias lograr un aprendizaje significativo en sus alumnos, el 25\% de los docentes menciona que el beneficio que se obtienen al implementar estrategias es un aprendizaje significativo en el alumno, el otro $25 \%$ establece que es el interés por aprender más en clases, el $25 \%$ piensa que es para que el alumno se interese más en la clase y por último el $25 \%$ restante establece que es para motivar la clase. Los factores que influyen para tomar la decisión de una estrategia son: la mitad de los docentes afirma que es el estilo de aprendizaje de los alumnos y la otra mitad dice que es el tema que se estéllevando a cabo. Más de la mitad de los docentes toma frecuentemente en cuenta el perfil de sus alumnos. La dificultad que se presenta para los docentes con más frecuencia al aplicar una estrategia es vincular los temas con la estrategia. La mitad de los docentes menciona que los recursos que intervienen son los económicos en la aplicación de estrategias, el 25\% dice que son los recursos humanos y el $25 \%$ final menciona que son los recursos didácticos, económicos, humanos y factores sociales.

\section{Entrevista a padres. Santa María}

El día 11 de noviembre se hicieron cuatro entrevistas a los padres de familia de la Telesecundaria no. 346 localizada en la comunidad de Santa María. El 50\% de los padres de familia mencionan que las estrategias son lo más importante porque son recursos que ayudan a la correcta representación del conocimiento en el alumno, mientras el $25 \%$ menciona que solo son reforzamientos para que los alumnos entiendan mejor el tema, así el 25\% restante solo menciona que son importantes. Mencio- 


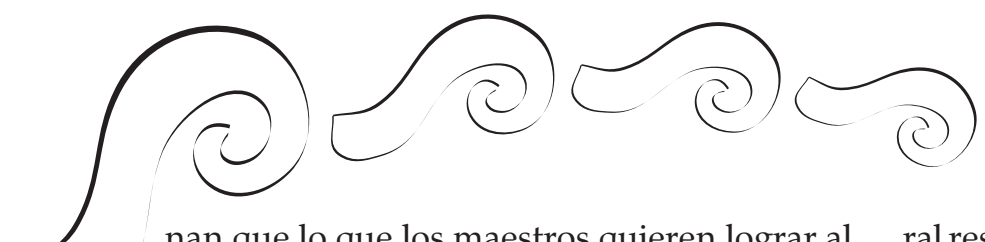

nan que lo que los maestros quieren lograr al implementar estrategias es: en un $25 \%$ que los alumnos repasen los visto en clase, el otro $25 \%$ que los alumnos tengan un aprendizaje que les permita resolver diferentes situaciones, el siguiente $25 \%$ que los alumnos usen las estrategias para que estudien en casa y el $25 \%$ final menciona que es para cumplir lo que la escuela dice. Más de la mitad de padres de familia dice que se da cuenta que las estrategias que les aplican los docentes a sus hijos les sirven porque hacen tareas con entusiasmo y sin dudas, es así como el $25 \%$ piensa que se ve reflejado en sus calificaciones. El 50\% de los padres de familia considera que el factor interno de la escuela que influyen en sus hijos es la forma en que aprenden y el otro $50 \%$ piensan que son los recursos disponibles. La mitad afirma que la dificultad que hay para que los maestros apliquen estrategias es la falta de convivencia en el salón, sin embargo el $25 \%$ dice que es la carencia de recursos y el otro $25 \%$ piensa que es el poco conocimiento de tipos de estrategias. El 50\% de los padres afirman que lo que interviene para que sus hijos tengan un mejor desempeño en la escuela es el trabajo colaborativo entre comunidad escolar y padres. El $25 \%$ dice que es la alimentación balanceada y el $25 \%$ restante afirma que es maestros con buen desempeño académico.

\section{Resultados}

Se realizó una investigación en cuatro escuelas de la zona 55 ubicada en la sierra de Hidalgo, en los municipios de Juárez y Tlahuiltepa, en cuatro comunidades integradas a la zona: San Lorenzo Itztacoyotla, Santa María, San Nicolás y Acapa, donde se aplicaron instrumentos de investigación con el propósito de identificar qué factores intervienen para que los docentes implementen estrategias de enseñanza-aprendizaje en el aula en Telesecundarias.

Los resultados que se obtuvieron en la investigación cualitativa fueron los siguientes:

En las cuatro comunidades, lo que se extrajo de los instrumentos aplicados fueron en gene- ral resultados positivos: el 12.5\% de los padres, así como el $92.3 \%$ los maestros y el $45.8 \%$ los alumnos, coinciden con que lo más importante de la aplicación de estrategias de enseñanzaaprendizaje es el aprendizaje significativo, esto también se debe a que como menciona Díaz "son procedimientos que el agente de enseñanza utiliza en forma reflexiva y flexible para promover el logro de aprendizajes significativos en los alumnos" (Díaz, 2002, en http://www.monografias.com) por lo tanto, se está cuidando dicha parte del aprendizaje.

El $29.1 \%$ de los padres y el $66.6 \%$ de alumnos de estas comunidades consideran que las estrategias de enseñanza-aprendizaje son importantes para el desempeño académico ya que como refiere González "las estrategias son una vía para que la multiplicidad de significados que se trabajan y comparten en la clase conecten el conocimiento privado que el alumno posee con el conocimiento público que el profesor pretende enseñar" (González, 2003, p.3), por lo que los sujetos tienen claro que las estrategias entonces sí son de gran utilidad.

Cuando se habla sobre "qué factores influyen en la implementación de las estrategias de enseñanza-aprendizaje", el 34.4\% de los maestros, padres y alumnos, llegan a una respuesta en común que es la forma en que aprenden los alumnos; esto no es raro, ya que la misma autora Díaz establece que "uno de los aspectos importantes que se consideran para saber qué estrategia es la indicada o adecuada en ciertos momentos de la enseñanza es considerar qué características generales tienen los aprendices "nivel de desarrollo cognitivo, conocimientos previos, factores motivacionales, etc." ( Díaz y Hernández, 2002, p.141) por lo que entra en el marco sobre lo que nuestros entrevistados respondieron.

Los resultados fueron aplaudidos ya que el $50 \%$ de los alumnos aseguran no encontrar dificultades en la implementación de estrategias de enseñanza-aprendizaje por parte de los docentes, esto muestra bajo su perspectiva que existe un aprendizaje satisfactorio por parte de los alumnos y buena aplicación de 


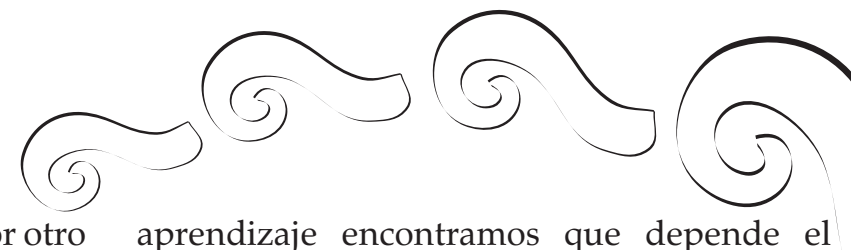

estrategias por parte de los docentes, por otro lado, se podría decir que se cumple con lo que la Secretaría de Educación Pública menciona, que es "que las estrategias se integran con actividades que fortalecen la propuesta curricular, si bien no todas son obligatorias, expresan un carácter prioritario en su implementación ya que en conjunto con el plan de estudios y el diseño institucional conforman la columna vertebral que da soporte a la estructura del modelo pedagógico de Telesecundaria", esto define la tarea del docente como un mediador que complementa el aprendizaje de sus alumnos y se preocupa por sus logros académicos .(SEP, 2012)

\section{Conclusiones}

En la investigación llevada a cabo en el municipio de Juárez y Tlahuiltepa, se tuvo una experiencia muy exitosa, ya que se obtuvo información relacionada con el tema a investigar, los factores que intervienen para la implementación de estrategias enseñanzaaprendizaje en el aula en Telesecundarias.

Con respecto al problema a investigar, se perseguía detectar cómo el maestro determina el uso de cada estrategia que va a aplicar a los alumnos y qué factores principales intervienen para usar una estrategia, al respecto se detectó que son: el estilo de aprendizaje de cada alumno y el tema que se está llevando a cabo lo que determina qué estrategia se va a usar. Los factores que más intervienen son los recursos materiales y humanos.

\subsection{Respuestas a las preguntas de investiga- ción}

En cuanto a las preguntas de investigación planteadas inicialmente, lo que los instrumentos nos arrojaron fue lo siguiente:

Los factores que más toman en cuenta los docentes para aplicar una estrategia son el estilo de aprendizaje de los alumnos y el tema que se esté llevando a cabo. Respecto a los factores educativos y sociales, determinan la implementación de estrategias de enseñanza-

aprendizaje encontramos que depende el contenido de la materia y los factores didácticos, económicos, sociales, etc., para la aplicación de las estrategias y es importante establecer que en una parte sí se rigen por lo que el libro establece para implementar las estrategias.

Con referencia a los recursos materiales, humanos, tiempo e infraestructura influyen en la implementación de estrategias de enseñanzaaprendizaje, el 25\% de los entrevistados coincidieron que en la mayoría de los casos lo que más influye son los recursos materiales y humanos, ya que comentan que ellos se tienen que adaptar a los materiales que se les puedan brindar, por lo que son comunidades alejadas de la ciudad que carecen de distintos recursos.

\subsection{Cumplimiento de los objetivos.}

El objetivo general planteado nos permitió definir de manera correcta cómo es que los docentes deciden el uso de las estrategias de enseñanza-aprendizaje, y obtener así como resultado los factores que más influyen, que son los estilos de aprendizaje de los alumnos, el propósito de crear en los alumnos un aprendizaje significativo y los recursos materiales disponibles, además se cumplió con la aportación de una antología portadora de estrategias preinstruccionales, cointruccionales y posinstruccionales, que ayudarán a integrar la práctica del docente y a crear una educación de calidad.

En cuanto a los objetivos específicos, se pudo identificar la efectividad de las estrategias al tener como resultado que más del $50 \%$ contestó que las estrategias que implementan sus maestros los ayudan a estudiar en casa, ya que las usan como métodos de estudio.

Igualmente se determinó cómo es que deciden la aplicación de estrategias según el tema y los recursos con los que cuentan los maestros y se elaboró una antología de 18 estrategias para complementar la práctica educativa de los docentes, lo que fomentó el aprendizaje de calidad en los alumnos. 


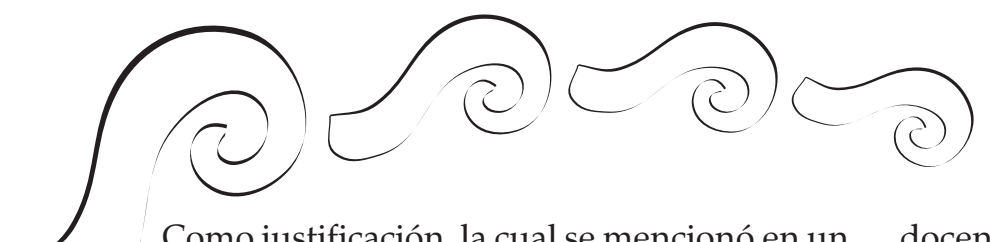

Como justificación, la cual se mencionó en un inicio, esta investigación tiene una relación con Proyecto Educativo Regional Lasallista Latinoamericano ya que nos invita a transformar la sociedad por medio de un servicio educativo dirigido especialmente a comunidades marginadas (PERLA, 2011). Nos dirigimos hacia la urgencia "educación de calidad" donde se encuentra la necesidad de: reconocer a los docentes como importantes protagonistas del cambio y hacer de su formación una prioridad. Al hablar de calidad también se refiere a la calidad académica, ¿Qué es lo que se enseña? ¿Cómo se enseña? ¿Cuándo se enseña?, así como la conformación de redes para elegir las herramientas pedagógicas adecuadas y las estrategias a implementar en el aula y todo el ambiente educativo en el cual se encuentre el docente, de este modo se ven beneficiados:

1. Los maestros para que tengan herramientas necesarias y puedan brindar una educación completa a los alumnos.

2. Los alumnos para que tengan una educación de calidad que les permita desarrollar desde sus conocimientos hasta sus habilidades.

3. La institución en general para elevar el prestigio de su institución ya que ésta brindará una educación con un alto nivel académico.

Los maestros, alumnos y padres de familia fueron beneficiados de manera que con los resultados que expone esta investigación, en determinado caso los maestros; podrán retroalimentar su práctica docente e incrementar cada vez más la calidad en sus contenidos, formas de enseñar e implementación de estrategias; los padres podrán concienciar la importancia de las estrategias de enseñanzaaprendizaje como un elemento primordial para la calidad del desempeño académico de sus hijos; y los alumnos podrán gozar de una educación de calidad y buenos propósitos.

\subsection{Aportaciones y limitaciones del trabajo}

Al analizar las aportaciones y limitaciones centrales del trabajo a las que nos enfrentamos, identificamos las estrategias que los

docentes aplican en su práctica educativa cotidiana, las dificultades a las que se enfrentan para la aplicación de estrategias y nos dimos cuenta de el propósito de la implementación de estrategias, el cual nos llevó a conocer que los docentes quieren lograr un aprendizaje significativo en los alumnos.

Las limitaciones con las cuales nos encontramos es que algunas de las personas no entienden el término de estrategia, por lo que tuvimos que exponer el significado.

En la comunidad de Acapa no pudimos contar con la presencia del director, en ese caso, tuvimos que dejar su entrevista en blanco.

\subsection{Recomendaciones}

Proponemos a estas comunidades como sugerencias de mejora:

- Invitar a los padres de familia a más talleres o pláticas que tengan que ver con el desarrollo integrador de sus hijos, exhortarlos de manera que no tengan que ir solo porque un programa se lo pide, sino porque consideran motivador eimportante el taller para su rol de padres.

- Fomentar en los maestros la implementación de estrategias que sirvan para el inicio, el desarrollo y el final de la clase.

- Que los maestros tengan una gama de estrategias para aplicar, que se relacionen con el tema que están viendo y adaptar las estrategias a las áreas de trabajo.

- Trabajo colaborativo de padres de familia y docentes.

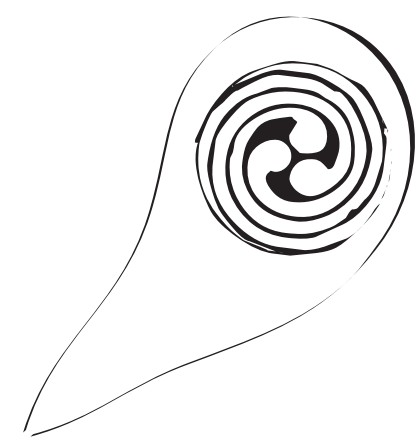




\section{Fuentes de consulta:}

Díaz, F y Hernández, G. (2002). Estrategias docentes para un aprendizaje significativo. Una interpretación constructivista. México D.F.: Mc Graw - Hill.

González Ornelas, V. (2003). Estrategias de enseñanza y aprendizaje. México: Pax México.

Hernández Sampieri, R., Fernández-Collado, C., \& Baptista Lucio, P. (2006). Metodología de la investigación (4 ed.). México, D.F.: Mc Graw Hill

Lasallista, R. L. (2011). PERLA Proyecto Educativo Regional Lasallista Latinoamericano. Bogotá: Colombia

Monereo, C., Castelló, M., Clariana, M., Palma, M., \& Pérez, M. L. (2007). Estrategias de enseñanza y aprendizaje (12ª ed.). México, D.F: Graó.

Monografías. (s.f.). Obtenido de Estrategias de enseñanza-aprendizaje: http://www.monografias.com/trabajos57/estrategias-aprendizaje/estrategias-aprendizaje2.shtml [recuperado el 9 de Septiembre del 2014]

Páez , I. (2006). Estrategias de aprendizaje -investigación documental- . Redalyc .

Secretaría de Educación Pública. (2012). Obtenido de http://telesecundaria.dgme.sep.gob.mx/ docs/TS-ESTRATEGIAS-REFORZAMIENTO.pdf [ recuperado el 9 de Septiembre del 2014]

Telesecundaria 11 EDUSAT. (s.f.). Obtenido de http://televisioneducativa.gob.mx/ index.php/info/que-es-la-telesecundaria [ recuperado el 9 de Septiembre del 2014]

Kholer, J. (2005). Importancia de las estrategias de enseñanza y el plan curricular. Redalyc .

(s.f.). Obtenido de La importancia de las estrategias de aula: http://www.quadernsdigitals.net/ datos_web/hemeroteca/r_1/nr_17/a_212/212.htm [ recuperado el 9 de Septiembre del 2014]
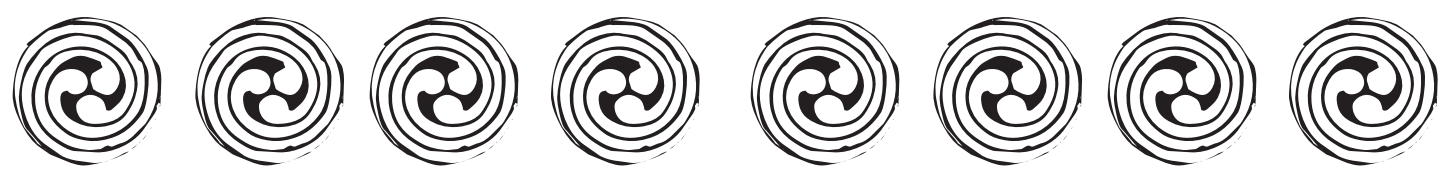
Anexos

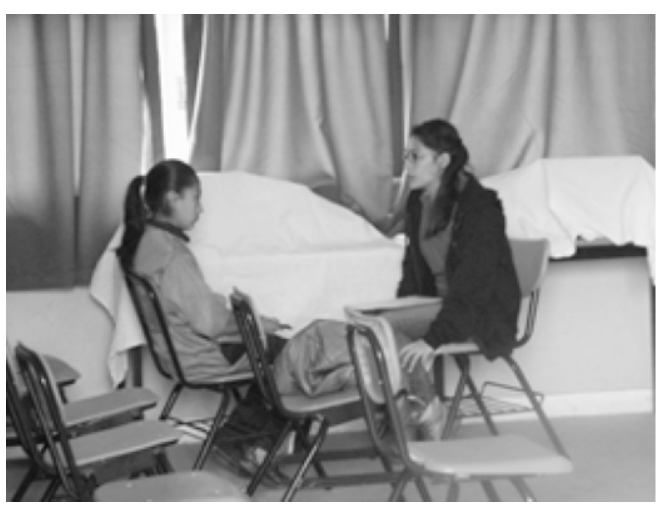

Entrevista a alumna de Santa María.

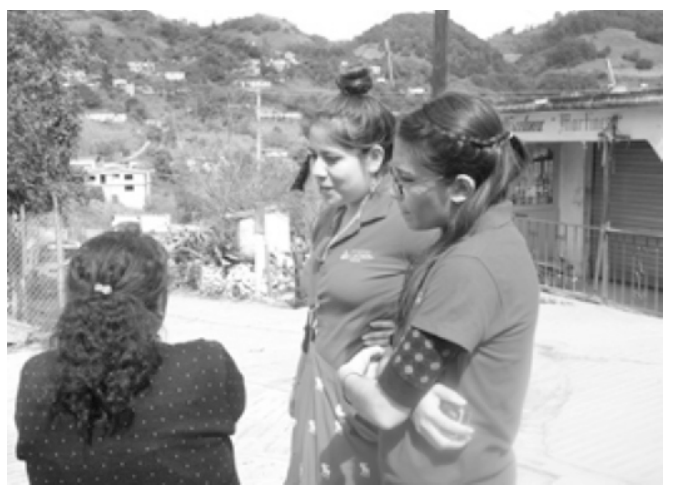

Visiteo a la comunidad en Santa María.

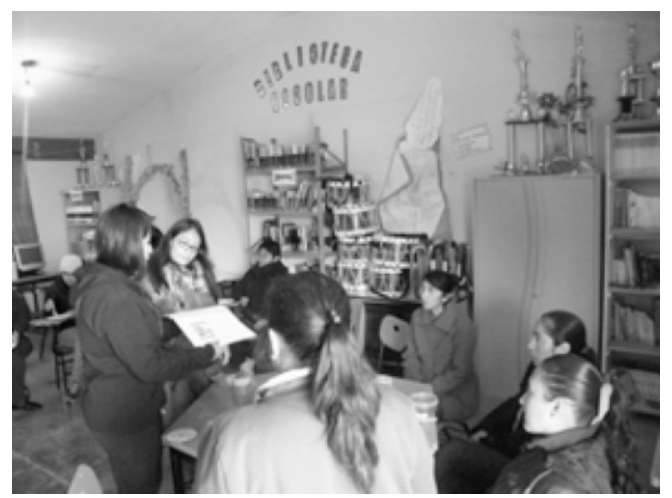

Taller donde se presentó la antología a los maestros de la comunidad de Acapa.

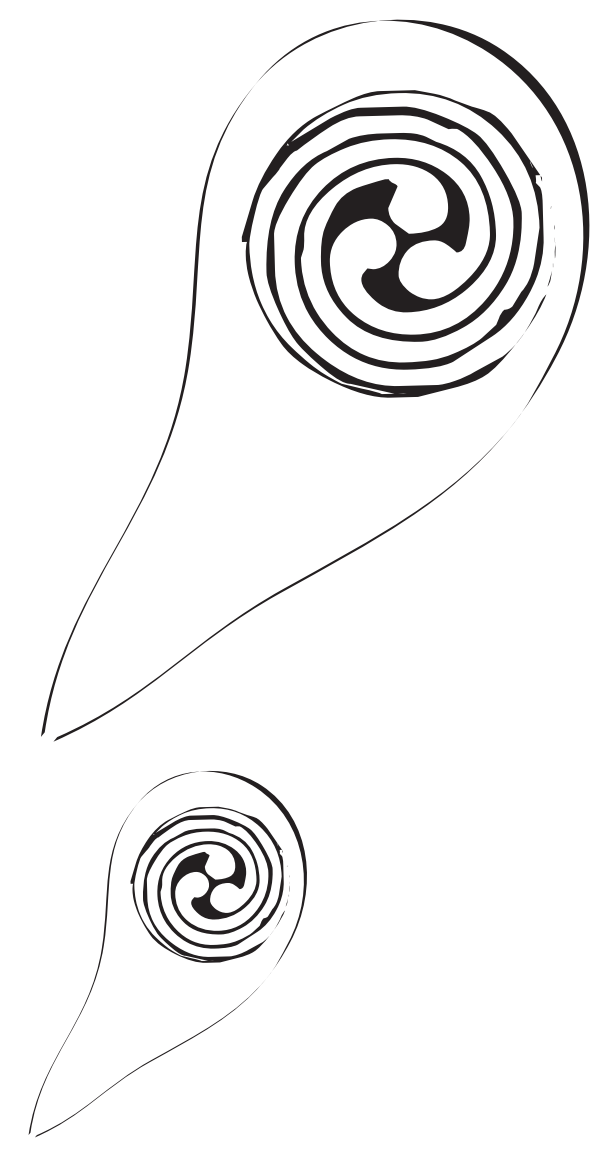

